\title{
Captopril-induced acute renal artery thrombosis and persistent anuria in a patient with documented pre-existing renal artery stenosis and renal failure
}

\author{
P. S. WILliams \\ M.R.C.P.
}

\author{
M. S. HENDY \\ M.R.C.P.
}

\author{
P. ACKRILL \\ F.R.C.P. \\ Artificial Kidney Unit, Withington Hospital, West Didsbury, Manchester M20 8LR
}

\begin{abstract}
Summary
We describe an elderly man, with pre-existing renal failure and atheromatous renal artery stenosis, who developed persistent anuria due to renal artery thrombosis after acute hypotension following captopril administration. Caution should be used when captopril is first administered to patients with impaired renal function in whom renal artery stenosis is known or suspected.
\end{abstract}

KEY WORDS: renal artery thrombosis, captopril, hypotension.

\section{Introduction}

Captopril is a potent pharmacological agent used in the treatment of renin-dependent hypertension. Its main activity is in inhibiting angiotensin-I-converting enzyme. Recent reports have indicated that the dramatic fall in blood pressure which may follow captopril therapy can cause reversible renal failure (Planz and Bundschu, 1980; Kawamura et al., 1982). Reversible renal failure occurring without hypotension has been reported in three patients by Silas et al. (1983) all of whom were found to have renal artery stenosis affecting a single functioning kidney and in 11 patients by Hricik et al. (1983) with severe hypertension associated with either bilateral renal artery stenosis or renal artery stenosis in a single kidney. The mechanism of this decrease in renal function is thought to result from a disturbance of glomerular filtration consequent to blockade of the renin-angiotensin system in the presence of decreased renal artery perfusion pressure (Hricik et al., 1983). Interstitial nephritis causing reversible renal failure secondary to captopril therapy has also been reported (Farrow and Wilkinson, 1981; Hooke et al., 1982). We now report a patient with documented preexisting poor renal arterial blood supply in whom captopril induced renal artery thrombosis and subsequent persistent anuria.

\section{Case report}

A 66-year-old man was admitted to hospital in November 1982, for stabilization of his hypertension of $2 \frac{1}{2}$ years known duration. In June 1981, he had had an abdominal aortic bifurcation graft inserted for aneurysmal dilatation. Pre-operative angiography had revealed aneurysmal dilatation of the aorta from below the renal arteries to the common iliac vessels (Fig. 1). There was complete occlusion of the right renal artery. The right kidney was supplied by a branch of the right ureteric artery. The left renal artery was stenosed by atheromatous plaques. The pre-operative blood urea was $15.7 \mathrm{mmol} / 1$ and creatinine $0.157 \mathrm{mmol} / 1$ and showed no significant deterioration 4 months later.

When admitted to hospital in November 1982 his blood pressure was recorded as $240 / 120 \mathrm{mmHg}$ (lying) and $180 / 100 \mathrm{mmHg}$ (standing). Blood urea $18.4 \mathrm{mmol} / 1$ and creatinine $0.182 \mathrm{mmol} / 1$. His usual antihypertensive medications (labetalol, clonidine, amiloride and hydrochlorothiazide) were continued and captopril, $25 \mathrm{mg}$ thrice daily, was introduced. Three hours after the first dose the blood pressure was recorded as $80 / 55 \mathrm{mmHg}$ (lying) and $75 / 55$ $\mathrm{mmHg}$ (standing). The patient remained hypotensive but uncomplaining for the next $\mathbf{4 8} \mathrm{hr}$. After receiving seven $25 \mathrm{mg}$ tablets the captopril was stopped. The patient was transferred to our care after 3 days of anuria. High dose intravenous urography failed to reveal any nephrograms and there was no uptake on screening with technetium diethylene triamine pentaacetic acid. Aortography revealed no evidence of patency in either renal artery and no nephrogram was observed in either kidney. Oblique films showed 


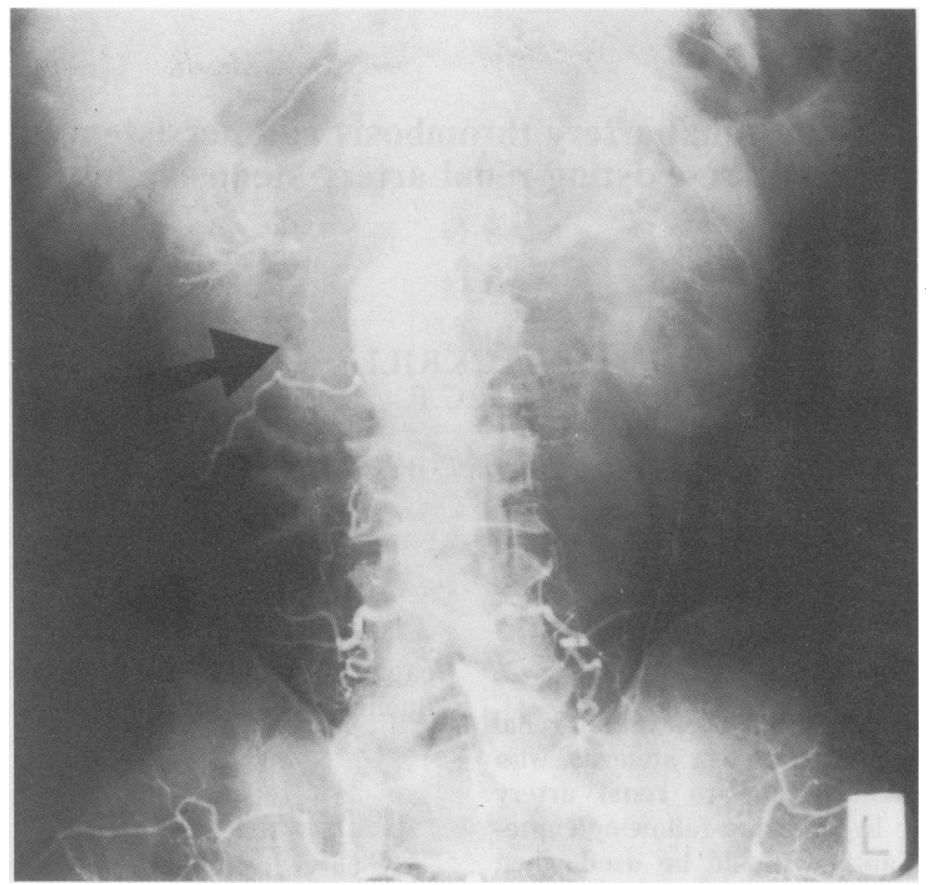

FIG. 1. Abdominal aortogram showing aneurysmal dilatation. There is also atheromatous stenosis of the left artery and no evidence of 30 patent right renal artery. The right kidney is supplied by a branch (arrowed) of the right ureteric artery.

a blind stump of a renal artery on the left side. He was maintained on intermittent peritoneal dialysis but remained anuric until cardiac arrest 2 months later.

\section{Discussion}

The left renal artery thrombosis was almost certainly due to the fall in blood pressure caused by captopril treatment. As thrombosis of the abdominal aorta affecting the right renal artery had already occurred the result was anuria. Renal artery thrombosis of a single functioning kidney secondary to antihypertensive treatment has only been reported on one previous occasion; atenolol was incriminated in this case (Shaw and Gopalka, 1982). In patients with two functioning kidneys thrombosis of an already severely narrowed renal artery has been reported during treatment with the angiotensin converting enzyme inhibitor enalapril (Hodsman et al., 1983a) and occluded renal arteries were found in three patients on captopril therapy by de Zeeuw (Hodsman et al., 1983b) but this was not, at that time, related directly to the treatment. However, in a review by Hollenberg (1983) of 269 patients treated with captopril, no episodes of renal artery thrombosis were recorded.

Both distal aortic thrombosis and renal artery thrombosis may be clinically silent (Sabiston, 1982) Thrombosis of a stenosed renal artery during anti hypertensive treatment can easily be missed. Thi\& appears to have happened in the case we describe. I has been suggested that in patients with known rena artery stenosis, and high renin activity or sa黑 depletion captopril is likely to cause acute hypoten sion (Collste et al., 1979). We recommend that in the event of a profound fall in the blood pressure ai immediate graded infusion with angiotensin as previo ously described (Hodsman et al., 1983c), be given of if this is not available, normal saline should be infused. Also following our experience with two other patients with renovascular hypertension, both of whom had precipitous falls in blood pressure after $\mathrm{D}$ single $25 \mathrm{mg}$ dose of captopril, it is now our policy to administer an initial dose of $1 \mathrm{mg}$ captopril (in lactose carrier) and monitor blood pressure quarte hourly for $4 \mathrm{hr}$. Following this we continue on ther second day with $3 \cdot 125 \mathrm{mg}$ captopril-increasing incrementally according to response. Twenty-five patients have been treated in this way and only one of these required specific corrective measures for treat ment of an acute hypotensive episode following a mg dose of captopril.

Captopril is often used in the treatment of hyperitension that has proved resistant to other available therapeutic agents. In this context the response to 
captopril is good; approximately $75 \%$ achieving complete control with either captopril alone or in combination with a diuretic (Hollenberg, 1983). However, there is considerable evidence that the renin-angiotensin system plays a crucial part in regulating the glomerular filtration rate when renal perfusion pressure is low (Blythe, 1983). The administration of captopril to patients with bilateral renal artery stenosis or renal artery stenosis affecting a single kidney tends to result in acute deterioration in the glomerular filtration rate which is usually reversible if captopril administration is stopped (Blythe, 1983). We have shown that acute hypotension following captopril administration can cause irreversible renal failure in a patient with renal artery stenosis affecting a single functioning kidney. Captopril should be used with caution in hypertensive patients with known or suspected bilateral renal artery stenosis or renal artery stenosis and a solitary kidney.

\section{References}

BLYTHE, B.B. (1983) Captopril and renal autoregulation. New England Journal of Medicine, 308, 390.

Collste, P., Haglund, K., Lundgren, G., Magnussen, G. \& OSTMAN, J. (1979) Reversible renal failure during treatment with captopril. British Medical Journal, 2, 612.

FARROW, P.R. \& WILKINSON, R. (1979) Reversible renal failure during treatment with captopril. British Medical Journal, 1, 1680

Hodsman, G.P., Brown, J.J., Cumming, A.M.M., Davies, D.L., EAST, B.W., LeVER, A.F., MORTON, J.J., MURRay, G.D., ROBERTSON, I. \& RobertSON, J.I.S. (1983a) Enalapril in the treatment of hypertension with renal artery stenosis. British Medical Journal, 287, 1413.
Hodsman, G.P., Brown, J.J., Cumming, A.M.M., EAST, B.W., LEVER, A.F., MORTON, J.J., MURRAY, G.D. \& ROBERTSON, J.I.S. (1983b) Enalapril (MK 421) in the treatment of hypertension with renal artery stenosis. Journal of Hypertension, 1, (suppl. 1) 109.

Hodsman, G.P., Isles, C.G., MuRray, G.D., Usherwood, T.P., WEBB, D.J. \& ROBERTSON, J.I.S. (1983c) Factors related to firs dose hypertensive effect of captopril: prediction and treatment. British Medical Journal, 286, 830.

Hollenberg, N.K. (1983) Medical therapy of renovascular hypertension: efficacy and safety of captopril in 269 patients. Cardiovascular Reviews and Report, 4, 852.

HoOKe, D., WAlker, R.G., WAlTer, N.M., D'APICE, A.J.F., WHITWORTH, J.A. \& KINCAIDE-SMITH, P. (1982). Repeated renal failure with the use of captopril in a cystinotic renal allograft recipient. British Medical Journal, 285, 1538.

Hricik, D.E., Browning, P.J., Kopelman, R., Goorno, W.E., MADIAS, N.E. \& DZAU, V.J. (1983) Captopril-induced functional renal insufficiency in patients with bilateral renal-artery stenosis in a solitary kidney. New England Journal of Medicine, 308, 373.

KaWAmURA, J., OKADA, Y., NishibUChI, S. \& YoshidA, O. (1982) Transient anuria following administration of angiotensin-1converting enzyme inhibitor (S Q 14225) in a patient with renal autotransplantation. Journal of Urology, 127, 111.

PlanZ, G. \& BUNDSChU, H.D. (1980) Zunehmende Niereninsuffizienz nach Blutdrucksenkung mit Captopril bei maligner Hypertonie. Klinische Wochenschrift, 58, 897.

SABISTON, D.E. JR. (1982) Disorders of the arterial system. In: Textbook of Surgery. (Ed. J.C. Sabiston), p. 1939. W. B. Saunders, Philadelphia.

SHAw, A.B., GolPalKa, S.K. (1982) Renal artery thrombosis caused by antihypertensive treatment. British Medical Journal, 285, 1617.

Silas, J.H., KlenKa, Z., Solomon, S.A. \& Bone, J.M. (1983) Captopril induced reversible renal failure: a marker of renal artery stenosis affecting a solitary kidney. British Medical Journal, 286, 1702.

(Revised version accepted 8 February 1984) 